\title{
Word and the Americanist perspective
}

Van Gijn, Rik ; Zúñiga, Fernando

\begin{abstract}
Even though recently appeared reference grammars of lesser-known languages usually do pay attention to issues to do with wordhood, studies of the theoretical and typological import of wordhoodrelated questions in indigenous languages of the Americas are not numerous. This publication aims to address the challenges posed by individual phenomena found in the Americas to the received views of wordhood.
\end{abstract}

DOI: https://doi.org/10.1007/s11525-014-9242-z

Posted at the Zurich Open Repository and Archive, University of Zurich

ZORA URL: https://doi.org/10.5167/uzh-99717

Journal Article

Accepted Version

Originally published at:

Van Gijn, Rik; Zúñiga, Fernando (2014). Word and the Americanist perspective. Morphology, 24(3):135160.

DOI: https://doi.org/10.1007/s11525-014-9242-z 


\title{
Word and the Americanist perspective
}

\author{
Rik van Gijn • Fernando Zúñiga
}

Received: 19 March 2014 / Accepted: 1 October 2014 / Published online: 14 October 2014

(C) Springer Science+Business Media Dordrecht 2014

\begin{abstract}
Even though recently appeared reference grammars of lesser-known languages usually do pay attention to issues to do with wordhood, studies of the theoretical and typological import of wordhood-related questions in indigenous languages of the Americas are not numerous. This publication aims to address the challenges posed by individual phenomena found in the Americas to the received views of wordhood.
\end{abstract}

Keywords Phonological word · Grammatical word · South American languages · Clitics - Affixes · Morphology

$\begin{array}{ll}\text { Abbreviations } \\ \text { A } & \text { subject of transitive verb } \\ \text { ABS } & \text { absolutive } \\ \text { ABST } & \text { absential } \\ \text { ACC } & \text { accusative } \\ \text { AV } & \text { affix vowel } \\ \text { COMP } & \text { complementizer } \\ \text { COMPL completive } \\ \text { DAT } & \text { dative } \\ \text { DIR } & \text { direct } \\ \text { DU } & \text { dual } \\ \text { EMPH } & \text { emphatic } \\ \text { ERG } & \text { ergative } \\ \text { EVID } & \text { evidential }\end{array}$

R. van Gijn ( ()

Dept. of comparative linguistics, University of Zürich, Plattenstrasse 54, 8032 Zürich, Switzerland e-mail: erik.vangijn@uzh.ch

F. Zúñiga

Department of Linguistics, University of Bern, Länggassstrasse 49, 3012 Bern, Switzerland 


$\begin{array}{ll}\text { FOC } & \text { focus } \\ \text { GEN } & \text { genitive } \\ \text { g-word } & \text { grammatical word } \\ \text { IND } & \text { indicative } \\ \text { INTR } & \text { intransitive } \\ \text { IRR } & \text { irrealis } \\ \text { LOC } & \text { locative } \\ \text { M } & \text { masculine } \\ \text { N } & \text { neuter } \\ \text { NEG } & \text { negative } \\ \text { NOM } & \text { nominative } \\ \text { NS } & \text { nominal suffix } \\ \text { PFV } & \text { perfective } \\ \text { PL } & \text { plural } \\ \text { POSS } & \text { possessed } \\ \text { PRF } & \text { perfect } \\ \text { PROG } & \text { progressive } \\ \text { PRS } & \text { present } \\ \text { PST } & \text { past } \\ \text { p-Word } & \text { phonological word } \\ \text { REL } & \text { relativizer } \\ \text { SG } & \text { singular } \\ \text { TA } & \text { transitive animate } \\ \text { THM } & \text { theme } \\ \text { TOP } & \text { topic } \\ \text { TR } & \text { transitivizer } \\ \text { TV } & \text { theme vowel } \\ \text { VER } & \text { veracity } \\ & \end{array}$

\section{Introduction}

The last decade has seen a renewed interest in the different notions of word used from theoretical, descriptive, and comparative perspectives. One notable development is the fact that the importance of the distinction between phonological or prosodic words on the one hand and syntactic or grammatical words on the other has become widely recognized in cross-linguistic and typological studies. Following older seminal work (e.g. Zwicky and Pullum 1983), for example, Dixon and Aikhenvald (2002) and Anderson (2005) discuss phonological and syntactic dependency as seen in various and varied language-specific phenomena that may allow to distinguish between word, affix, and several kinds of clitics. More recent work, however, stresses the problematic nature of both the grammatical word (e.g. Haspelmath 2011) and the phonological word (e.g. Bickel et al. 2009; Schiering et al. 2010) in particular from a cross-linguistic perspective.

Even though recently appeared reference grammars of lesser-known languages usually do pay attention to such issues (cf. also Aikhenvald 2002; Dixon 2002; 
Rankin et al. 2002; Woodbury 2002 and Tuttle 2008), studies of the theoretical and typological import of wordhood-related questions in indigenous languages of the Americas are not numerous. This publication aims to address the challenges posed by individual phenomena found in the Americas to the received views of wordhood.

The remainder of this introductory paper serves to embed the papers of the special issue in a theoretical and-to some extent-historical context. In Sect. 2 we start with a concise overview of approaches to the notion of word, focusing on the distinction between a phonological word (p-word) and a grammatical word (g-word). Section 3 is dedicated to mismatches between p-words and g-words, focusing in particular on different types of clitics. In Sect. 4, we propose an outline of a typology of morphological units based on a number of relevant parameters. Section 5, finally, focuses on what the Americanist perspective may contribute to the general debate on word, taking the different papers of the special issue as an example.

\section{The p-word and the g-word}

Dixon (1977) argues for the necessity of the notion of a phonological word, separately from the syntactic word on the basis of data from the Australian language Yidiny. In Yidiny "a grammatical word consists of a whole number of (one or more) phonological words" (p. 27). For Yidiny it is necessary to make a distinction between a group of (monosyllabic) affixes that are part of a larger phonological word, and a group of (disyllabic and post-inflectional) affixes that start a new phonological word within a grammatical word. In other words: A grammatical word needs to be established on the basis of morphosyntactic criteria, the phonological word on the basis of phonological criteria, and they need not coincide.

Although opinions are still divided on the separation of the phonological and the grammatical word, there seems to be a growing body of evidence in favor of such a distinction, and of the fact that they do not necessarily align (see e.g. Hall 1999; Hall et al. 2008). However, there are still many issues that remain unresolved or contested both for the p-word and the g-word. We will briefly discuss both types of word and some of the problems associated with them.

The canonical grammatical word is often defined on the basis of a number of characteristics that relate to the grammatical word as a syntactic unit, i.e. a unit whose internal structure is invisible to the syntactic component and whose distributional properties are determined by syntax (see e.g. Zwicky 1985; Matthews 1991; Dixon and Aikhenvald 2002). ${ }^{1}$ Although the grammatical word is generally seen as less controversial than the phonological word, there are serious problems with the definition of the g-word as well. In a recent paper, Haspelmath (2011) reviews 10 criteria that have been brought to bear by different authors on the issue of wordhood (given below) and concludes that none of them singles out a universal category of word. The 10 criteria are the following:

\footnotetext{
${ }^{1}$ We grant that in many languages — not in the least American languages — the determination of the order of grammatical words, especially at the clausal level, is a matter of pragmatics rather than syntax. But the important point here is that the positional rules are not morphological in nature.
} 
Fig. 1 The prosodic hierarchy (Hall 1999:9)

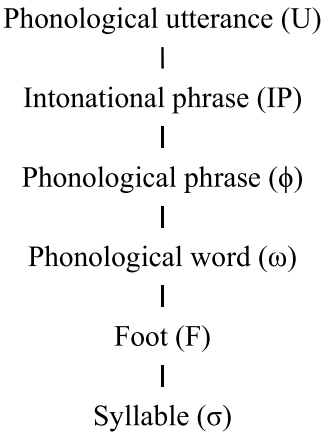

1. Potential pauses (possible between words, not within)

2. Free occurrence (possible for words, not parts of words)

3. Mobility (words are mobile, affixes fixed)

4. Interruptability (possible within phrasal combinations, not within words)

5. Selectivity (affixes select a specific host, words do not)

6. Non-coordinatability (word can be deleted under identity, parts of words cannot)

7. Anaphoric islandhood (anaphors can refer to words, not parts of words)

8. Nonextractability (words can be extracted, parts of words cannot)

9. Morphophonological idiosyncrasies (stem-affix combinations, but not host-clitic combinations tend to show morphophonological idiosyncrasies)

10. Bi-uniqueness (violations of the one-form-one-meaning principle tend to occur in morphology, not in syntax)

Haspelmath shows that none of these criteria is watertight and that there are many exceptions to each rule. Haspelmath's discussion (as well as - to a lesser extent - the one by Zwicky (1985)) shows that, like the p-word, the g-word is highly problematic as well. It leads Haspelmath to the conclusion that we should abandon the idea of a universally applicable notion of g-word. In his view, the grammatical word exists either as language-specific concept, or cross-linguistically at best as a fuzzy concept.

Many theories of phonological wordhood assume a hierarchy of constituents that can be generalized as in Fig. 1 (Hall 1999:9). Early exponents of this approach are Booij (1983), Selkirk (1984), and Nespor and Vogel (1986). In these approaches, the phonological word is not only defined vis-à-vis the grammatical word, but also with respect to other, both smaller and larger phonological domains. Their basic position is that utterances can be divided into different prosodic constituents, which form the domain for different kinds of phonetic, segmental, or prosodic rules. In this way, each of these domains can be characterized in terms of the rules that apply to that domain.

There are a number of points of controversy, or unresolved issues with respect to the hierarchy given in Fig. 1. There are at least three important points on which linguists may disagree: (i) the nature of the relation between the different layers of the prosodic hierarchy; (ii) the universality of the prosodic hierarchy; (iii) the nature of the relation between the units of the prosodic hierarchy and other modules of language.

The first point of divergence is how the different levels relate to each other. Early work in prosodic hierarchies, e.g. Selkirk (1984) and Nespor and Vogel (1986) intro- 


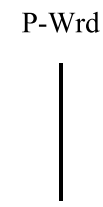

$\mathrm{PrPhr}$

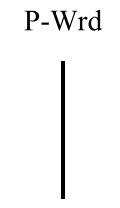

$<$ no foot $>$
P-Wrd

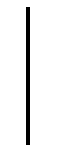

Syllable

*exhaustivity
P-Wrd

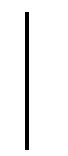

P-Wrd

*layeredness

*headedness

*non-recursivity

Fig. 2 Structures disallowed by the Strict Layer Hypothesis

duced a Strict Layer Hypothesis, broken down into four separate claims in Anderson (2005:47), on the basis of Inkelas (1989)—see also Selkirk (1995). ${ }^{2}$

Layeredness

Headedness

Exhaustivity
No $C^{i}$ dominates a $C^{j}$ where $j>i$

Every $C^{i}$ directly dominates some $C^{j}$ where $j \geq i-1$

No $C^{i}$ directly dominates a $C^{j}$ where $j<i-1$

Non-recursivity No $C^{i}$ directly dominates another $C^{i}$

These four constraints rule out the following structures:

The leftmost structure of Fig. 2 is prohibited by the layeredness constraint because prosodic, or phonological phrases are higher up in the hierarchy than p-words, and so phonological phrases contain p-words, but not the other way round. The second structure requires the p-word to be built up out of feet, so p-words without feet are disallowed. The third structure, prohibited by exhaustivity disallows the skipping of a layer in the Prosodic Hierarchy, that is: all syllables must be grouped into feet, all feet must be grouped into p-words etc. The last structure is prohibited by the nonrecursivity rule that disallows hierarchical relations between layers of the same rank.

The validity of the last two constraints, exhaustivity and non-recursivity, has been questioned. ${ }^{3}$ In Optimality Theory approaches (Prince and Smolensky 1993), they are typically maintained, but as violable constraints (see Selkirk 1995; Peperkamp 1997; Anderson 2005), so that in some cases, some of the structures in Fig. 2 are in fact allowed if higher-ranked contradictory constraints need to be satisfied.

A second point of contention is more fundamental, as it relates to whether the levels in Fig. 1 constitute a universal structure. There are two relevant questions here: one is whether all languages have at least these levels, another question is whether all languages have at most these levels. Schiering et al. (2010), focusing on the prosodic word in Vietnamese (Austroasiatic) and Limbu (Sino-Tibetan), answer both questions in the negative. Reviewing a number of general prosodic rules of Vietnamese they conclude that, although there is relatively uncontroversial evidence for syllables and phonological phrases, there is no empirical basis for positing a prosodic word domain

\footnotetext{
${ }^{2}$ In the claims, $C$ refers to any layer in the prosodic hierarchy, the superscripts serve to distinguish different layers from each other.

${ }^{3}$ The first two relate to the very architecture of the prosodic hierarchy, and questioning these implies questioning the whole enterprise. We will discuss these types of more fundamental criticisms below.
} 
in Vietnamese. Limbu illustrates a challenge to the second question in that it seems to have more levels of prosodic structure than proposed by the Prosodic Hierarchy. The authors propose a prosodic structure for Limbu that has two types of prosodic word: a minor prosodic word, which is required to account for some of the prosodic rules of the language $([1] \sim[\mathrm{r}]$ alternation and [?]-insertion, which exclude prefixes from their domain), and a major prosodic word as the domain for other rules (stress placement and labial place assimilation).

Rather than assuming a universal structure with possible exceptions (whether or not regulated by constraint interaction) or by assuming extra universal prosodic domains, Schiering et al. (2010) defend the view that "prosodic domains are languageparticular, intrinsic and highly specific properties of individual phonological rules or constraints" (p. 700). As such, if a language has particular domains on which a number of different phonological rules cluster, they represent frequency patterns of language use. This view of prosodic structure is confirmed in a more comprehensive cross-linguistic study carried out by the same authors (Bickel et al. 2009). Interestingly, they find that language-specific prosodic structure is a diachronically rather stable feature, which tends to be consistent within families, and not areally determined.

A third important question is how the structure as given in Fig. 1 relates to nonprosodic units of information. The least problematic levels in this respect are arguably the syllable and the foot. These lower levels correspond to phonological information. The phonological word, however, is " $(. .$.$) the lowest constituent of the prosodic hi-$ erarchy which is constructed on the basis of mapping rules that make substantial use of non-phonological notions. In particular, the phonological word $(\omega)$ represents the interaction between the phonological and the morphological components of the grammar" (Nespor and Vogel 1986:109).

Different proposals have been brought forward to deal with this mapping of the gword and the p-word. It is quite clear that, even for advocates of a universal syntactic and prosodic structure, that the mappings between these two are language-specific. Broadly speaking two types of proposals have been brought forward to deal with these language-specific mappings, either through a rule system, or an algorithm (e.g. Nespor and Vogel 1986) or, within the context of Optimality Theory, by ranked constraints (e.g. Selkirk 1995; Anderson 2005).

The focus in Nespor \& Vogel is on the prosodic rules that define the different phonological constituents and more in particular the prosodic rules. They do give a few general comments concerning the mapping rules, which describe the role of this interface component in their model. For the morphological component in particular they say (1986:17-18):

[T]hey [i.e. the mapping rules, RG \& FZ] need to be able to make reference to what we will call the morphological word (...). In addition, it is necessary to distinguish simple (underived) words from complex (derived and compound) words (... ). In this regard, furthermore, the rules that build phonological structure must have access to the stem of the word (...) and to any inflectional or derivational affixes. 
Similarly, the phonological component needs to have access to surface ${ }^{4}$ syntactic units and configurations to the extent that they have a bearing on the application of phonological rules to a specific prosodic constituent. The semantic component includes what most linguists today would regard as a separate module of pragmatics. Syntax and 'semantics' are particularly relevant to higher-level constituents.

Several contributions within the framework of Optimality Theory (OT) take a different approach. In OT a relation between an input and an output of a linguistic form is assumed, which is mediated by a set of constraints. Although these constraints are assumed to apply without reservations, the different constraints of a language differ in their importance, or ranking, so that one constraint can be overruled by another. In this way, OT approaches to wordhood generally assume a set of constraints that align the phonological word with the grammatical word (see e.g. McCarthy and Prince 1993; Selkirk 1995; Peperkamp 1997; Anderson 2005) but these constraints can be overruled by others, such as those that were proposed as part of the basic architecture of the Prosodic Hierarchy (see discussion above). In this way, in different languages there may be mismatches between grammatical and phonological words. We discuss the types of mismatches that may arise in the next section.

\section{Mismatches between the grammatical and phonological word}

As mentioned above, it is probably a general point of consensus that, even though phonological words and grammatical words do not necessarily align, they do in fact align in the canonical instance of a word. This is, as was mentioned above, explicitly acknowledged by OT accounts of words, by the family of alignment constraints but also in other accounts (e.g. Spencer and Luís (2012), who elaborate a proposal in the context of Canonical Typology (Corbett 2005), Dixon and Aikhenvald (2002) in a more general descriptive-typological framework, and implicitly in earlier work on words, affixes, and clitics such as Zwicky (1977, 1985), Zwicky and Pullum (1983)).

In principle, and assuming that there has to be at least some overlap between the phonological and grammatical word, this would lead to a typology where the following three options are predicted to occur:

1. Coincidence of $\mathrm{p}$-word and g-word

2. The g-word is smaller than the p-word

3. The p-word is smaller than the g-word

The bulk of this section (and the remainder of the paper as well as most papers in the special issue) will be devoted to situation 2 ( $\mathrm{p}$-word $>$ g-word), but the third situation (p-word $<$ g-word) is certainly also encountered. In fact, as mentioned above, the situation in Yidiny that paved the way for the phonological word was such that one grammatical word could contain more than one phonological word. Here we briefly examine the data of Yidiny as an illustration of situation 3.

\footnotetext{
${ }^{4}$ Nespor \& Vogel use a generative model of syntax, but conclude that deep syntax, and in particular the postulation of empty categories, yields the wrong predictions, and so should be left out of consideration as far as their prosodic model is concerned.
} 
Yidiny has an intricate but relatively clear-cut domain that can be associated with the prosodic word. A number of phonological rules and principles (see Dixon 1977 for a full account) make reference to this domain, such as a rule that lengthens the penultimate syllable of PWords with an odd number of syllables (p. 6), and a rule that - subject to certain conditions - deletes the final vowel of a suffix to avoid the creation of a PWord with an odd number of syllables (p. 11). Rule 2 applies after rule 1 . There are also relatively clear rules for what a grammatical word is: grammatical words in Yidiny have a single final inflectional morpheme and distributional freedom. The following examples count as single grammatical words, but two phonological words (Dixon 1977:28)

$\begin{array}{ll}\text { Yidiny [PAMA-NYUNGAN] } & \\ \text { guma:rridaga: } \mathrm{n}^{\mathrm{y}} & \\ \text { gumari-daga- } \mathrm{n}^{\mathrm{y}} \mathrm{u} & \text { morphological structure } \\ {\text { g gumari }]_{\omega}\left[\text { dagan }^{\mathrm{y}} \mathrm{u}\right]_{\omega}}^{\text {'became red }} & \text { prosodic structure }\end{array}$

In (1), there are two vowel lengthening processes operating, one lengthening the penultimate syllable of the underlying penultimate syllable of the entire grammatical word, and another lengthening the second syllable of the entire grammatical word. Both lengthening processes are unexpected on a reading of a coinciding p-word and g-word, which would not predict any lengthening, given that there is an even number of syllables. Moreover, the final vowel deletion of the suffix $-n^{y} u$ is also unexpected in a prosodic structure of an even number of syllables. These unexpected facts are explained if one assumes two prosodic words of three syllables each. The odd number of syllables explains both lengthening processes and the final vowel deletion of the suffix.

The mismatch as in (1) can be generalized by distinguishing between what Dixon calls 'cohering' (i.e. those suffixes that integrate into the prosodic structure of their morphological host) and 'non-cohering' affixes (those that start a new phonological word, such as -daga in (1). Non-cohering suffixes are either disyllabic affixes (whether derivational or inflectional) and every post-inflectional affix, independently of number of syllables (Dixon 1977:27).

The situation in Yidiny is by no means an 'exotic' structure found exclusively in lesser-known languages. For instance, a similar situation holds for Dutch, which also has cohering and non-cohering affixes (see Booij 1999). Dutch p-word-level main stress placement is a rather complex affair, the specifics of which need not concern us here (see Booij 1999 for a detailed analysis). The important point for our purposes is that, once the position of main stress is established, a secondary stress pattern is created on the basis of trochaic feet created from left to right, avoiding stress clashes (two adjacent syllables with stress). If a root is followed by a noncohering suffix, such as the similative suffix -achtig [axtəy], this results in a structure normally prohibited by the fact that stress clash is avoided (Booij 1999:113).

$$
\begin{aligned}
& \text { Dutch [INDO-EuropeAn, GERMANIC] } \\
& \text { [ró }^{\mathrm{w}} \text { t?àxtəy] }
\end{aligned}
$$




$\begin{array}{ll}\text { rood-achtig } & \text { morphological structure } \\ {[\text { rood }]_{\omega}[\text { achtig }]_{\omega}} & \text { prosodic structure } \\ \text { 'red-like' } & \end{array}$

In (2) two adjacent syllables are stressed. The fact that the stronger stress is on the first of these syllables has to do with a leftmost stress assignment rule that applies to grammatical words that contain more than one prosodic word (like most compounds) crucially after the main stress rule and secondary stress rule apply for each prosodic word individually. ${ }^{5}$

The situation where one phonological word contains more than one grammatical word has received much more attention in the literature than the opposite situation. More specifically, a vast literature has been devoted to the study of clitics. It is well beyond the scope of this paper to discuss in detail the many scholarly contributions, both empirical and theoretical, that have appeared in the last 35-odd years. Rather, we focus on what we think are the key points in the discussion.

In the same year that Dixon defended positing a phonological word for Yidiny, Arnold Zwicky also published a highly influential working paper in which he proposed a typology of clitics (Zwicky 1977). Since this paper, together with a few others by Zwicky and colleagues (Zwicky and Pullum 1983; Zwicky 1985) shaped the ensuing discussion to a considerable degree, it is worth dwelling on Zwicky's early work, in particular in terms of the criteria for determining clitichood and in terms of classifying different types of clitics.

Zwicky (1977) starts the discussion on both these topics. The spirit of the paper is to defend the view that clitics form a separate class of morphological units, distinct from words and affixes, a perspective refined in later papers, e.g. Zwicky and Pullum (1983) and Zwicky (1985). Zwicky (1977:2-3) mentions 6 criteria that are of importance for distinguishing words from affixes, briefly summarized here:

i. Ordering: The syntagmatic ordering of affixes is rigid, that of words is more flexible.

ii. Internal sandhi: Phonological rules that apply at the word level do not apply across word boundaries, but they do apply across root-affix junctures.

iii. Binding: Affixes are morphologically bound whereas words can be freestanding elements.

iv. Construction with affixes: Affixes attach to bases or other affixes (there is no intermingling of morphology and syntax).

v. Rule immunity: Syntactic rules like equi-deletion cannot apply to affixes but can apply to words.

vi. Accent: Affixes do not bear independent accent, words do.

Zwicky shows, making reference to the Austronesian language Madurese, that the combined application of these criteria can be found wanting if the goal is to neatly

\footnotetext{
${ }^{5}$ Some constructions with -achtig are lexicalized combinations and as such are analyzed as a single prosodic word, like reusachtig [ $\varnothing^{\mathrm{y}} \mathrm{z}$ záxtəy] 'enormous' (lit. giant-like), where there is a single stressed syllable, following the main stress rule, and prevocalic voicing of the voiceless fricative /s/ to [z] before the suffix takes place. A similar pattern holds for some lexicalized compounds (see Booij 1999:116).
} 
distinguish between words and affixes, and that the intermediate category of clitics differs from both.

Zwicky and Pullum (1983) builds on Zwicky (1977) and offers a list of criteria that focus on distinguishing clitics from affixes (the letters are in keeping with the original):

A. Clitics can exhibit a low degree of selection with respect to their hosts, while affixes exhibit a high degree of selection with respect to their stems.

B. Arbitrary gaps in the set of combinations are more characteristic of affixes than clitics.

C. Morphological idiosyncrasies are more characteristic of affixes than clitics.

D. Semantic idiosyncrasies are more characteristic of affixes than clitics.

E. Syntactic processes can affect affixed words, but not clitic groups.

F. Clitics can attach to material already containing clitics, but affixes cannot.

Zwicky (1985) looks towards the other end of the spectrum, and focuses on how clitics differ from words. He proposes a number of tests that fall into different categories (slightly summarized from the original).

G. Phonology: Clitics cannot form a phonological word on their own, whereas words can and typically do. Internal sandhi and p-word-level prosody apply within phonological words, and so should affect clitics, whereas external sandhi and p-phrase prosodic rules should not affect clitics.

H. Morphology: Clitics are more affix-like than words in several respects:

a. morphological boundedness (clitics are morphologically bound, words are not)

b. ordering (clitics are in-between words and affixes when it comes to their position)

c. distribution (like affixes the principles governing the distribution of clitics are often simple, i.e. often based on a single principle-although there is more complexity than in affix placement generally)

d. internal complexity (clitics are like affixes and unlike many words in that they are usually not morphologically complex).

I. Syntax: Clitics are not full syntactic units like words are, and therefore should be immune to syntactic rules like deletion under identity, replacement by a proform under identity and, and movement (clitics cannot be moved from their base position on their own).

Especially the criteria mentioned in Zwicky and Pullum (1983) are still widely used to determine clitichood of a given element. Criteria A-I indicate quite nicely that clitics fall in between words and affixes on phonological, morphological, and syntactic grounds. Note that this does not necessarily solve the status of the clitic as a morphological unit. Zwicky (1985:285) indicates that most of the tests mentioned above have their exceptions, and calls them "lists of symptoms" (Ibid.) and that "intervening factors can prevent even clear cases from exhibiting a certain symptom, and a particular symptom might result from some condition other than the one at issue" (Ibid), so that in fact there is no one criteria that can unequivocally 'prove' word, clitic, or affix-status of some element.

In a recent paper, Spencer and Luís (2012) present a different perspective on the problem of clitics. They approach clitics within a framework of Canonical Typology 
(Corbett 2005) and define a canonical (function) word ${ }^{6}$ and a canonical affix. They mention 6 characteristics of canonical function words that can be contrasted with their 5 characteristics of canonical affixes, which are to be seen as violable constraints (Spencer and Luís 2012:127-129).

\section{Canonical (function) word constraints}

1. A (function) word is coextensive with the minimal prosodic word

2. A (function) word is minimally bimoraic

3. A (function) word respects the phonotactic constraints of the prosodic word

4. A (function) word is placed with respect to the edge of the syntactic phrase bearing the functional property expressed by the function word

5. A (function) word is not phonologically dependent on another word

6. A (function) word canonically takes wide scope over a coordinated phrase with which it is in construction

\section{Canonical affix constraints}

1. An affix consists of a monomoraic syllable.

2. An affix is placed to the right of a word

3. An affix is placed with respect to the word whose functions/lexical relatedness features it realizes

4. The domain of an affix is the (canonical) word

5. An affix is integrated morphophonologically into the structure of the word form of which it is a part.

The function word constraints outline an element that forms a phonological word of its own (1-3 and 5), and that is in construction with syntactic units rather than morphological (4 and 6). The affix constraints outline an element that is phonologically dependent on or integrated into a host domain $(1,5)$ and an element that is in construction with a morphological unit (2-4). Characteristic 2 moreover expresses a universal tendency that languages have a preference for suffixes over prefixes.

Starting out with this opposition, they conclude that clitics cannot be associated with any unique criterion, but simply form different constellations of properties that are in one way or another a mix of the word constraints and the affix constraints, such that the canonical clitic lies at the intersection of the orthogonal characteristics of word- and affix-characteristics, and is in a sense a negatively defined unit.

The other influential line of inquiry started by Zwicky (1977) is that of the classification of different types of clitics. Zwicky recognizes three classes of clitics: simple clitics, special clitics, and bound words. Simple clitics are reduced variants (i.e. not associated to a phonological word of their own) of free forms that have the same distributional properties as their non-reduced counterpart. Special clitics are also reduced variants of free forms, but this time with their own special syntax, deviating from the distributional behavior of the non-reduced counterpart. Bound words, finally, are clitics that do not have an unreduced counterpart.

\footnotetext{
${ }^{6}$ They focus on function words because their problematic morphological status is one of the main targets of the paper, but the function word constraints are to a large degree word constraints (except maybe constraint 4).
} 
Anderson (2005:31) criticizes Zwicky's classification on the grounds that "all of the characteristics of the clitic itself are ideally to be accounted for as 'local' [i.e. not making reference to the existence of an unreduced counterpart-RG \& FZ] properties of that element". Instead, Anderson proposes a two-way classification of parameters involved in clitichood into phonological clitics and morphosyntactic clitics. A phonological clitic is "a linguistic element whose phonological form is deficient in that it lacks prosodic structure at the level of the (Prosodic) Word" (Anderson 2005:23). A morphosyntactic clitic is "A linguistic element whose position with respect to other elements of the phrase or clause follows a distinct set of principles, separate from those of the independently motivated syntax of free elements in the language" (ibid. 31). Zwicky's simple clitics would fall into the class of phonological (but not morphosyntactic clitics), whereas the special clitics are morphosyntactic clitics (as well as phonological clitics usually). Bound words (abandoned by Zwicky in later work) would fall into one of these classes and no longer form a separate class.

In the next section, we will take a position that builds on Anderson's account in that it does not make reference to non-reduced counterparts. In addition, it incorporates further morphosyntactic aspects. It deviates from Anderson's position in that it goes well beyond the identification of only clitics.

\section{Towards a typology of morphological units}

It should have become clear from the previous discussion that the notion of word has many dimensions, referring to different modules of language, and none of them is absolutely watertight in its own right. In fact, the proposed criteria seem to be orthogonal in that an element can be a word according to one criterion, but not according to another, as is discussed in Haspelmath (2011), among others.

It is clear, then, that a dichotomy approach with a sharp demarcation line between words and affixes has little hope of success. What we set out to do here, therefore, is not so much to give a definition of the word, but rather to approach wordhood on the basis of orthogonal parameters from different domains of language structure. In this perspective, a canonical word (which is a theoretical vantage point rather than an entity actually found in natural languages) is defined as the point of convergence of certain settings for each of these parameters. Likewise, canonical affixes are defined by the opposite set of parameter settings. This approach to charting the variation space of a certain phenomenon is based on Canonical Typology (e.g. Corbett 2005, 2006, Brown et al. 2012). This canonical type is neither more nor less than a calibration point and in principle indifferent to whether it has any empirical representation: it may be very common, it may be extremely uncommon, or it may even not exist at all. One might say it is an extreme point of a fuzzy category. Once this extreme point has been established, phenomena encountered empirically in languages of the world can be compared to this canonical point, and situated in the variation space with respect to it.

As discussed above, many different criteria have been proposed for wordhood, clitichood, and affixhood. These criteria can roughly be divided into four groups, the first group relating to p-wordhood, the latter two to g-wordhood. 


\section{Phonological form properties}

- No internal pauses

- Adherence to minimal p-word requirements

- Internal sandhi

- Prosodic independence on p-word level

Distributional properties

- Positional freedom

- No host selectivity

- Free occurrence

Lexical integrity properties

- Coordinatability/equi deletion

- Non-interruptability

- No word-internal syntax

- Anaphoric islandhood

- Extractability

Simplicity and transparency properties (of clitics and clitic-host combinations)

- Paradigmatic and syntagmatic regularity, both formal and semantic

- No internal morphological complexity

For our overview, we focus on the first two groups of criteria: phonological and distributional properties. Principles of lexical integrity may include potentially important criteria (see e.g. Booij 2009 in particular for non-interruptability) that can further enrich the typology, but they require detailed analyses, including negative data, which are not always available. This makes it difficult at this point to assess the extent of their effects on the typology. ${ }^{7}$ Moreover, for some of the lexical integrity criteria, it is questionable whether they tell us something about wordhood or rather about something else. Haspelmath (2011) discards anaphoric islandhood and extractability as arguments for wordhood, because the former is related to pragmatic status (referentiality) rather than wordhood, and the latter is a characteristic of phrases rather than words. For these reasons, we leave the study of the lexical integrity criteria for future research. Hopefully the publication of this special issue will contribute to the promotion of applying tests of lexical integrity to lesser known languages.

We also disregard the simplicity/transparency group, because they are not criterial in nature but rather probabilistic correlations: if there are irregularities in paradigms, they are most likely to represent root-affix combinations, but nothing follows from paradigms that do not show such irregularities. These criteria, moreover, imply that one needs to have a theory of what is an affix, clitic, or word before one can apply the criteria of transparency and regularity. Therefore, we have chosen not to make them part of our canonical typology of morphological units.

In the end, acknowledging to some extent the non-exhaustiveness of the typology, we are left with phonological and distributional criteria. The properties to do with phonological form all relate to the fact that affixes are canonically integrated

\footnotetext{
${ }^{7}$ It can furthermore be argued that criteria like non-interruptability and extractability are contained in the criteria of host selectivity and positional freedom in the sense that elements with very strict host specifications are not expected to be interruptible and elements with rigid placement possibilities are not easily extracted from their original place.
} 
into the p-word domain of their host: pauses within p-words are uncommon, minimal $\mathrm{p}$-word requirements are irrelevant for units that do not project a $\mathrm{p}$-word, and integration means that it adheres to the morphophonological, segmental, and suprasegmental rules associated with the p-word domain of the host. This leads to our first dimension:

1. Integration into phonological word (yes/partial/no). Words are canonically not integrated into the p-word domain of some other element, whereas affixes are canonically fully integrated. As some of the contributions to this special issue show, morphemes may show diverging behavior with respect to the degree to which they are integrated into the phonological word of their host even within languages. Therefore, this dimension may, and probably does, show considerable complexity. One of the empirical questions that need to be answered for this continuum is whether any regularities, dependencies, or implications exist with respect to the degree of phonological integration. We hope that the contributions in this book help to contribute to exploring this dimension.

Moving on to the g-word, the distributional principles can be brought back to two, one of which consists of two sub-dimensions.

2. Positional rigidity (yes/no). It has often been noted that words differ from affixes in that they are positionally more flexible, e.g. because placement of the former in the clause - even in syntactically rigid languages - may be influenced by informationstructural considerations, which is generally not the case with affixes. Whereas the canonical affix is positionally rigid, the canonical word is free. It is obvious that the settings for this parameter are not entirely discrete, as different degrees of flexibility and rigidness are bound to exist (e.g. relating to differences in the relative freedom of word order between languages). It is an open question whether or not this continuum is subject to restrictions. Positional rigidity is defined relative to host selection (see below): if an element is positionally restricted by the fact that it needs to appear next to a certain host, it can still be positioned flexibly with respect to that host.

3. The second distributional parameter refers to whether or not, in order to specify the position of a morphological element in a structure, reference needs to be made to another element relative to which the element in question is positioned. Whereas canonical affixes tend to have severe selection restrictions (i.e. low selection capabilities), grammatical words typically do not. This can be refined into the following mutually orthogonal subdimensions:

3.1 Host selection is determined by syntactic weight (yes/no). Phrasal affixes and phrasal clitics attach to constituents rather than stems, whereas canonical affixes attach to stems (i.e. syntactically light elements). Following this, we can make a distinction between elements whose position is determined by syntactic weight (they must be next to a syntactically light host) — prototypically affixes - and elements that (also) combine with phrases - typically words and clitics.

3.2 Host selection is determined by lexical category (yes/no). Affixes are prototypically positioned relative to an element of a specific lexical class, i.e., they subcategorize for a noun, a verb, or another lexical category. Words normally do not subcategorize for any hosts. Clitics may subcategorize for dif- 
Table 1 Properties of canonical words and affixes

\begin{tabular}{lllll}
\hline & $\begin{array}{l}\text { Phonological } \\
\text { INTEGRATION }\end{array}$ & $\begin{array}{l}\text { RIgID } \\
\text { POSItion }\end{array}$ & $\begin{array}{l}\text { Syntactic } \\
\text { WEIGHT }\end{array}$ & $\begin{array}{l}\text { LEXICAL } \\
\text { CLASS }\end{array}$ \\
\hline Canonical word & - & - & - & - \\
Canonical affix & + & + & + & + \\
\hline
\end{tabular}

ferent types of hosts. That this parameter is also orthogonal to the previous one (determination by syntactic weight) is shown by the fact that e.g. phrasal affixes, though they attach to a constituent, combine with a specific kind of constituent, that is, the constituent is required to have a specified (lexically determined) head. Second-position clitics, on the other hand, may for example attach to the first constituent of a clause irrespective of the lexical class of its head.

Thus, the extremes are characterized by positional freedom and the absence of any host or collocation restrictions on the one hand (canonical words), and by positional rigidity and severe collocation restrictions, both in terms of lexical class and syntactic weight, on the other (canonical affixes). The profiles of the canonical extremes are given in Table 1.

In what follows, we briefly discuss some examples that fall in between these extremes in one way or another, which serve to show the independence of the parameters.

Focus clitics in Cuzco Quechua The direct evidential $=m i($ shortened form $=n)$ in Cuzco Quechua (Southern Peru) attaches to focalized elements. The examples in (3) show that it attaches to different words and constituents, and at different positions in the clause (Faller 2002:18-19):

\section{Cuzco Quechua [QUECHUAN]}
a. $\quad$ pilar $=$ qa t'anta-ta $=\mathbf{n}$ mikhu-rqa-n
Pilar $=$ TOP bread-ACC $=$ EVID eat-PST-3
'Pilar ate bread.'

b. mana $=\mathbf{n}$ muchila-y-pi=chu ka-sha- $\mathrm{n}$

NEG $=$ EVID backpack-1-LOC $=$ NEG be-PROG-3

'It is not in my backpack.'

The position of the evidential marker is not determined by any strict host selection criteria, but rather by information-structural considerations. Nevertheless, the marker is phonologically integrated with the p-word of its host, as is evidenced for instance by the apocope of the final vowel of the marker. It differs minimally from the canonical word in that it is positionally free but phonologically integrated.

V2 in Germanic languages Dutch (as well as e.g. German) exemplify a case where an element that is associated with its own phonological word is positionally restricted: in main declarative clauses, it must occur as the second constituent, immediately fol- 
lowing the first constituent. There is no lexical restriction in that the first constituent may be of any type:

$$
\begin{aligned}
& \text { Dutch [INDO-EUROPEAN, GERMANIC] } \\
& \text { a. [ik] ga [morgen] [naar de stad] } \\
& \text { I go.1sG tomorrow to the city } \\
& \text { 'I go to the city tomorrow.' } \\
& \text { b. [morgen] ga [ik] [naar de stad] } \\
& \text { c. [naar de stad] ga [ik] [morgen] }
\end{aligned}
$$

Even though the inflected verb projects its own phonological word and its position is not determined by the syntactic weight or the lexical class of its neighbor, it is positionally rigid, thus presenting another minimal deviation from the canonical word. ${ }^{8}$

Phonologically independent, positionally flexible items, sensitive to syntactic weight but not lexical class (no example) A theoretically conceivable type of element with the description [[-phonological integration][-rigid][+syntactic weight][-lexical class]] would correspond to a unit which must be next to a syntactic end node, but they can be of different classes; the position with respect to this end node is furthermore flexible, and the element is not phonologically integrated with a host. We have not been able to find an example of this type of element. We come back to this issue at the end of the section.

German 'entgegen', Dutch 'uit' An example of an element that differs from canonical words only in terms of the requirement to be positioned next to a nominal constituent is the German adposition entgegen 'against' which can appear as either a preposition or postposition, i.e., either to the left or to the right of the nominal constituent (example from www.duden.de).

\section{German [INDO-EUROPEAN, GERMANIC]}

a. entgegen [meinem Rat] ist er abgereist against my.DAT advice is he.NOM left 'He left against my advice.'

b. [meinem Rat] entgegen ist er abgereist my.DAT advice against is he.NOM left 'He left against my advice.'

Although there is no difference in meaning between (5a) and (5b) and no difference in case assignment either, Duden ${ }^{9}$ notes that the postpositional use of entgegen is rare, which perhaps indicates that it is falling out of use.

Another potential candidate for this category of morphological unit is the Dutch adposition uit 'out (of)'.

\footnotetext{
${ }^{8}$ We are certainly not the first to compare the behaviour of V2 in Germanic in terms of parameters of wordhood. For instance, Wackernagel (1892) argued that finite verbs in proto-Indo-European were in fact clitics. Anderson (2005) argues that second-position clitics and V2 are both the result of an alignment operation positioning elements in the leftmost available syntactic position of an inflectional domain. Our position is not so much theoretical or diachronic, but rather descriptive.

${ }^{9} \mathrm{http} / / / \mathrm{www} . d u d e n . d e /$ rechtschreibung/entgegen_gegenueber_trotz.
} 


\section{Dutch [INDO-EUROPEAN, GERMANIC]}
a. Hij kwam uit [het bos]
He came out the forest
'He came out of the forest.'
b. Hij kwam [het bos] uit
He came [the forest] out
'He came out of the forest.'

In most cases the difference in position corresponds to a meaning difference in this language, where postpositions generally encode movement events, and prepositions stative events. However, in some constructions, such as the one in (6) this opposition is neutralized.

Moving one step further away from the canonical word and one step closer to the canonical affix, we now consider those cases that are a genuine mix, since they share half of their properties with canonical words and the other half with canonical affixes.

Phonologically independent, positionally flexible items, sensitive to syntactic weight and to lexical class (no example) An element that corresponds to the description [[-phonological integration][-rigid][+syntactic weight][+lexical class]] would be positionally associated with a word of a given lexical class, but it would not be phonologically integrated with it, and could appear either before or after it. We have not been able to find an example of this type of unit.

Phrase-final plural particle in Unua In Unua (Vanuatu), plurality is marked by a phonologically independent particle, that appears at the end of the noun phrase, whatever the internal structure of that noun phrase (Pearce 2012:82).

$$
\begin{aligned}
& \text { Unua [AUSTRONESIAN, OCEANIC] } \\
& \text { a. Dabos rin ra-vra re-b-ke-i xai. } \\
& \text { stranger PL 3PL-want 3PL-IRR-see-TR 2SG } \\
& \text { 'Strangers want to see you.' } \\
& \text { b. nagor nga m-i-pre-i rin } \\
& \text { cane COMP REL-3SG-take-TR PL } \\
& \text { 'the canes that he took' } \\
& \text { c. rroborum se raru rin } \\
& \text { child GEN 3DU PL } \\
& \text { 'their children [the children of they two]' }
\end{aligned}
$$

Mobile aspectual clitics in Nheengatú Aspectual clitics in Nheengatú (northwestern Brazil) normally attach to the final element of the verbal complex. However, when a negator proclitic is present, the aspectual clitics (here: $w \tilde{a}$ 'PFT') precede their host (da Cruz 2011:401):

$$
\begin{aligned}
& \text { Nheengatú [TUPÍ, TUPÍ-GUARANí] } \\
& \text { ti=wã=pe-su pe-kuntau } \\
& \text { NEG=PFV=2PL.A-go 2PL.A-speak } \\
& \text { 'You (PL) don't want to speak anymore.' }
\end{aligned}
$$


Veracity particle in Guajá Guajá (Maranhão, Brazil) has a number of particles that are positionally restricted but phonologically independent. The particle (a)té/(e)té (free variation) ${ }^{10}$ expresses an epistemic stance of veracity, and immediately follows syntactic end nodes of different types (verbs, nouns, adjectives, pronouns) (Magalhães 2007:118-119):

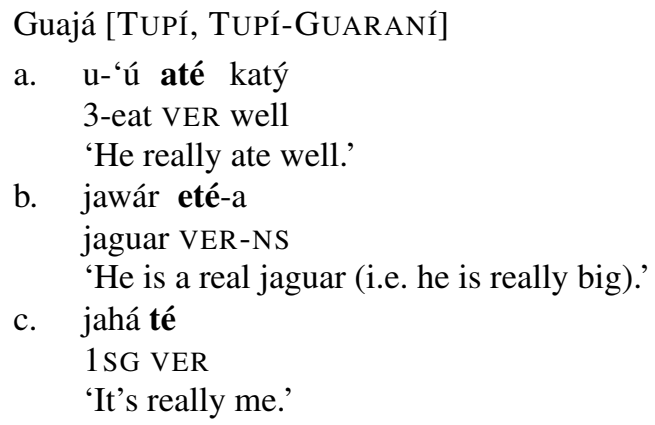

Mobile promiscuous affixes in Yuki A few grammatical markers in Yuki (Bolivia) show the tendency first of all to appear on elements of different lexical classes, and second on either side of these stems. The focus marker - no- and the past marker -keare examples of this (Villafañe 2004:168).

Yuki [TuPÍ, TuPí-GuARANí]

a. yagua bia-ño-ke yukia jaguar man-FOC-PST 3s.kill

'The man killed the jaguar.'

b. so-natut- $\tilde{1}$ ño-ke-bia u

meat-EMPH-EMPH FOC-PST-man 3s.eat

'The people ate a lot of meat.'

Second-position clitics in Cavineña Second position clitics attach to the first constituent of a clause or sentence, whatever the head of this constituent. They are positionally rigid, but their position is not determined by the lexical class of the constituent's head. An example comes from the Bolivian language Cavineña where person markers and their case markers attach to the first element, which may be any constituent. In complex sentences, the clitics attach to the end of the first clause. Example (11) shows three clitics (apparently the maximum) that are stacked onto the first constituent (Guillaume 2008:639).

$$
\begin{aligned}
& \text { Cavineña }[\text { TACANAN] } \\
& \text { ai=jatsu }=\text { tuke }=\mathbf{m i} \quad \text { ara-wa } \\
& \text { what }=\text { EXACTLY=3SG.ABS=2SG.ERG eat-PRF } \\
& \text { 'But what exactly did you eat?" }
\end{aligned}
$$

\footnotetext{
${ }^{10}$ There is another variant te, after words ending in /a/, but this seems not to be a general morphophonological rule of the language, and rather idiosyncratic to this particular particle. Moreover, the particles are stressed independently and show no prosodic dependency.
} 
Plural particle in Hawaiian Dryer (2013) reports, on the basis of Elbert and Pukui (1979), the marking of plurality in Hawaiian with a separate word that appears between the possessor and the head noun.

$$
\begin{aligned}
& \text { Hawaiian [AUSTRONESIAN] } \\
& \text { 'elua a'u mau i'a } \\
& \text { two my PL fish } \\
& \text { 'my two fish' }
\end{aligned}
$$

Mobile affixes in Huave Kim (2008) describes a number of affixes in the Mexican language Huave (San Francisco del Mar variety) that can either appear as prefixes or as suffixes. An example is the completive marker in (13) which appears as a prefix in the a-example, and as a suffix in the b-example (Kim 2008:234).

\section{San Francisco del Mar Huave [HuAvEAN]}

a. t-a-jch-ius

COMPL-TV-give-1

'I gave.'

b. pajk-a-t-u-s

face.up-AV-COMPL-INTR-1

'I laid face up.'

Kim argues that the position of the mobile affixes relative to their host is determined by phonological factors, to do with the optimal output in terms of syllabic structure.

Another, widely discussed, example that comes close to this type are the verbal clitics characteristic of Romance languages. However, although they do attach to either side of the inflected verb in some constructions, in others, like the one in (14) from Spanish, they seem to attach to a verb cluster.

$$
\begin{aligned}
& \text { Spanish [ROMANCE, INDO-EUROPEAN] } \\
& \text { a. [quiero ver] }=\text { te } \\
& \text { want.1SG.PRS.IND see }=\text { you } \\
& \text { 'I want to see you.' } \\
& \text { b. } \quad \text { te }=\text { [quiero ver] } \\
& \text { you }=\text { want.1SG.PRS.IND see } \\
& \text { 'I want to see you.' }
\end{aligned}
$$

Phrasal affixes in Yurakaré The theme marker $=j a$ in Yurakaré (central Bolivia) is an example of an element that attaches to a constituent, but it must be a noun phrase, comparable to the English phrasal possessive suffix -'s (Van Gijn 2006:63):

$$
\begin{aligned}
& \text { Yurakaré [ISOLATE] } \\
& \text { a. } \quad[\text { matata yee]=ja 'big woman' } \\
& \text { big } \quad \text { woman=THM } \\
& \text { b. } \quad[\text { yee matata]=ja 'big woman' } \\
& \text { woman big=THM }
\end{aligned}
$$


This is a familiar type of element, also present in e.g. English (possessor - 's, indefinite article $a(n)$ ), which is phonologically integrated (in the Yurakare example, the marker interacts with the stress pattern of the host), positionally rigid, the constituent they attach to must be of a specific type (NP/DP in these cases), but they do not have to attach to a syntactic end node.

Promiscuous person prefixes in Algonquian In many languages of the Americas, (part of) the verbal person markers are isomorphic with the nominal (possessive) person markers. For some language analysts, this is reason to regard them as clitics. One of the language families where this generally occurs is Algonquian; the following example is from Plains Cree (Wolfart 1996:412, 420):

$$
\begin{aligned}
& \text { Plains Cree [ALGONQUIAN] } \\
& \text { a. ni-wâpam-â-w } \\
& \text { 1-see.TA-DIR-3 } \\
& \text { 'I see him.' } \\
& \text { b. ni-sîsîp-im } \\
& \text { 1-duck-POSS } \\
& \text { 'My duck.' }
\end{aligned}
$$

As mentioned, the four parameters are simplified in that they are treated as binary. A last example will serve to show that the empirical reality is more complex.

Unintegrated affixes in Movima We saw when discussing data of Yidiny and Dutch in examples (1) and (2) above, as well as in the Hawaiian example (12) that units may be positionally rigid and underlie severe host selection restrictions, this does not mean that they must be integrated into the p-word domain of their morphological host. One of the problems that will be a recurring theme in this book is that the variability both between and within languages of degree of phonological integration is potentially rather great. As an example, consider the Bolivian Isolate Movima, whose person indexing morphemes attach to verbs, but integrate with this host to different degrees. One set of person markers, if syllabic, causes stress shift to the penultimate syllable, but show deviant behavior in other respects when compared to affixes. A second set of person markers is even less affix-like in that it does not participate in word stress. Both types of clitics - called internal and external cliticization by Haude, respectivelyand their behavior with respect to stress placement are shown in (17), from Haude (2006:98, 101), internal cliticization first, then external cliticization.

$$
\begin{aligned}
& \text { Movima [ISOLATE] } \\
& \text { [?onara'na?us] } \\
& \text { know }=\text { M.ABST } \\
& \text { 'He knows X.' } \\
& \text { b. iye:ni=as } \\
& \text { move }=\text { N.ABST } \\
& \text { 'It moves.' }
\end{aligned}
$$

The four parameters, considered as binary, are summarized in Table 2 . They predict 16 types of morphological units, most of which we have exemplified above. 
Table 2 The word-affix continuum

\begin{tabular}{lllll}
\hline & $\begin{array}{l}\text { PHONOLOGICAL } \\
\text { INTEGRATION }\end{array}$ & $\begin{array}{l}\text { Rigid } \\
\text { POSITION }\end{array}$ & $\begin{array}{l}\text { SYNTACTIC } \\
\text { WEIGHT }\end{array}$ & $\begin{array}{l}\text { LEXICAL } \\
\text { CLASS }\end{array}$ \\
\hline Canonical word & - & - & - & - \\
Focus clitics Quechua & + & - & - & - \\
V2 in Germanic languages & - & + & - & - \\
Mobile adpositions in German and Dutch & - & - & + & - \\
Phrasal particles Tapirapé & - & - & - & + \\
Mobile clitics Nheengatú & - & - & + & + \\
Veracity particle in Guajá & - & + & - & + \\
Mobile affixes in Yuki & + & - & - & + \\
2nd position clitics Cavineña & - & + & + & - \\
Plural in Hawaiian; person markers in & - & - & + & - \\
Movima & + & + & - & - \\
Mobile affixes in Huave & & + & + & + \\
Phrasal affix Yurakaré & + & - & + & + \\
Plains Cree person prefixes & + & + & - & + \\
Canonical affix & + & + & + & - \\
\hline
\end{tabular}

Two striking aspects immediately come to mind when looking at Table 2. First, our vocabulary to refer to elements that fall somewhere on this continuum is astonishingly poor, especially considering that we have only focused on concatenation and on a subset of parameters.

The second aspect is that not all rows have a corresponding example. There are two empty cells in the first column of the table, for which we have not been able to find examples. Future research should make clear whether this is because the relevant data fell outside our view or whether these hiatuses are in fact indicative of the nature of the word-affix continuum.

To tentatively anticipate a discussion on the second possibility, it does seem rather striking that the empty cells both refer to units that are phonologically unintegrated and positionally free. The only other unit (except for the canonical word) to have this constellation of characteristics, is the one exemplified by the German and Dutch mobile adpositions. Those were only partly convincing examples since, in the German case, one is much more frequent than the other, or, in the Dutch case, the interpretative difference between pre- and postpositions is neutralized only in certain environments. These facts may not be coincidental. A hypothesis that may follow from this overview is whether the (partial) lack of this group of units is related to the way morphological units develop over time, i.e. it may say something about likely diachronic paths, or about highly unstable synchronic situations that are generally avoided by languages. We could hypothesize that a grammaticalization path from an independent word towards an affix is more likely to start with the loss of phonological and positional freedom than with the loss of independence from syntactic weight or lexical class. 
As mentioned above, more parameters may have to be integrated into the typology to achieve a more complete picture. We hope that this overview, as well as the different papers in this special issue, contributes to the completion of such a typology.

\section{The present special issue: American perspectives}

As is well-known, languages can differ radically in terms of their morphological profiles. Different profiles give rise to different challenges for morphological theory. For instance, predominantly fusional languages, which are characterized by, among other things, nonlinear phonology, challenge a straightforward notion of the morpheme as a form-meaning unit. Different types of deviations from the one-form-one-meaning 'ideal' of the morpheme include portmanteau morphemes (1 form, $>1$ meaning), morphological zeroes (-form, +meaning), stem vowels (+form, -meaning), circumfixes ( $>1$ form, 1 meaning), to mention a few. Moreover, nonlinear morphological operations like vowel or consonant mutation, stress shift, tonal patterns have forced morphologists to accept a more abstract notion of the morpheme. In fact, this issue has given rise to an important division between lexical and inferential approaches to morphology, the latter assuming a very abstract idea of the (inflectional) morpheme (see Stump 2001 for a fuller overview). Perhaps due to the fact that many Indo-European languages show flectional tendencies, the nature of the morpheme has been a central debate in theoretical morphology. Nevertheless, languages with different types of morphological profiles certainly pose problems for theoretical morphology as well. For instance, it has been claimed for the analytic language Vietnamese that "there is no significant unit in Vietnamese intermediate between the syllable and the phonological phrase" (Thomas 1962:521, cited in Schiering et al. 2010:661). Vietnamese moreover poses problems for grammatical wordhood as well, because units "with a conventionalized meaning can be interrupted by phrasal elements" (Schiering et al. 2010:665). So where fusional languages pose problems for our idea of what a morpheme is because their morphological processes are so tightly intertwined, analytic languages may reveal problematic aspects of our ideas of word because their morphological processes present looser combinations than we are used to.

The indigenous languages of the Americas are mostly renowned for their highly synthetic verbal morphologies, where the morphemes within a verb are often related not only morphologically but also syntactically. These (poly-)synthetic structures raise yet other challenges for theoretical morphology. One general type of problem that has been discussed is the nature of the morphological component, especially as distinct from syntax. For instance, what is the syntactic status of incorporated (pro)nouns and their relation to the verb (see e.g. Mithun 2003). Another point where highly synthetic languages may pose problems for and eventually enrich morphology is in the area of affix ordering. Whereas one of the differences between words and affixes is assumed to be the relatively free distribution of words versus the rigid ordering of affixes, many languages with complex synthetic morphology show exceptions to that pattern, or they may show different ordering principles than a strict morphological templatic one (see Rice 2011 for an overview). Synthetic languages may also shed new light on the somewhat controversial phenomenon of so-called affixoids: bound, affix-like forms with specialized 
semantics that co-exist with a corresponding free lexeme (see e.g. Stevens 2005; Booij 2010:57-66).

The focus of this special issue is on another set of problems that may be associated with synthetic languages. If one considers concatenative morphemes as relatively recent grammaticalizations (compared to nonlinear morphological operations, for instance) it may be expected that problems arise with mismatches between p-words and g-words. After all, grammaticalization processes tend not to happen overnight, and not all aspects that are involved in grammaticalization (e.g. semantic bleaching, loss of distributional freedom, loss of phonological independence) necessarily happen in parallel ways. So a morpheme may be an affix in morphosyntactic terms, but it may still have (traces of) its phonological independence associated with it (see the discussion in the previous section), which will then interact with word-level phonological structure. Against such a background, at least three important lines of inquiry related to wordhood, which have been touched upon in individual papers of the present collection, seem to be particularly worth pursuing from an Americanist perspective. ${ }^{11}$

First, especially languages that allow for incorporation of lexical items into the verb complex may show interactions of different prosodic patterns. The main question here is whether the incorporated items retain (aspects of) their prosodic wordhood (creating structures as the ones discussed for Yidiny and Dutch above) or whether they are completely subordinate to the prosodic word structure of the host they are incorporated into.

Second, given that verbal g-words can sometimes be complete sentences, one might expect there to be more interaction between the prosodic word and higher-level domains, like the phonological and intonational phrase, including their interactions with syntax, information structure, and the like. In languages with such morphological profiles, the mappings between the non-prosodic domains and the prosodic ones can be expected to be more complex than originally suggested by Nespor \& Vogel's Prosodic Phonology.

Third, with a diachronic drive towards morphological synthesis, one would expect a picture of increased variability with respect to morphological units, where different units might show different behavior depending on their stage of development, as has been amply demonstrated in Sect. 4 above. This raises not only questions about the adequacy of typologies and theories of morphological units and prosodic domains, but also about the diachronic stability of prosodic domains (cf. e.g. Bickel et al. 2009).

Given the much improved situation of access to linguistic material in the Americas over the last few decades, we are at the beginning of an exciting period where we can start exploring issues like these systematically, and more firmly integrate the American perspective into theoretical thinking. Although it is clear that we did not aim for any kind of representative coverage of the Americas, we hope that the different contributions to the present special issue will offer some new ways of thinking about wordhood, and that the book will mark the starting point for future research

\footnotetext{
${ }^{11}$ This does of course not entail that this issue has not been discussed in the theoretical literature for instance with respect to clitics (see e.g. Spencer and Luís 2012 for an overview), approaches based on co-phonologies and prosodically dominant versus recessive affixes (see e.g. Inkelas 1998) as well as in the literature on affixoids (Booij, p.c.—see also Stevens 2005; Booij 2010). Nevertheless, American languages have often been underrepresented in the more theoretical debates.
} 
programs. In order to give an idea of the contents of this book, we briefly summarize the contributions.

The contribution by Fernando Zúñiga explores the continuum between prototypical words and prototypical affixes in Mapudungun. Apart from words (phonologically and distributionally independent elements) and affixes (phonologically and distributionally dependent), he also recognized clitics (phonologically dependent and distributionally independent) and anti-clitics (phonologically independent and distributionally dependent). In this way he shows that, although the facts of Mapudungun do not exactly fit received theoretical notions, there is a language-internal logic and consistent structure to the word-affix continuum.

Verónica Nercesian focuses on the word as a 'meeting point' for several modules of language, illustrated with data from Wichi. She argues that phonological and semantic conditioning of word forms is functional because it increases the transparency of word formation. Moreover, especially for (poly-)synthetic languages, the level of the word and that of the clause often overlap, so that syntactic relations are in fact achieved within the word. Nercesian therefore argues that, in particular at the level of the word, the different modules of language are not so neatly separated, but rather intertwined.

The paper by Jimena Terraza and Lorena Cayré Baito also focuses on Wichi, but the authors direct their attention to three types of word in that language: the phonological word, the grammatical word, and the orthographic word. They show that the domains of the phonological rules they discuss differ in their extension, stress being the most inclusive, and the principal indicator of $\mathrm{p}$-wordhood. Criteria for grammatical words additionally show that the clitics of the language display characteristics of both affixes and grammatical words. These facts raise the question what criteria are take into account when deciding what an orthographic word is. It appears that orthographic words are defined by the most encompassing phonological and grammatical criteria.

The contribution by Rik van Gijn focuses on metrical aspects of the phonological word in Yurakaré, which highlight a very intimate interaction at different levels between the p-word and other language domains, calling for highly specific mapping rules or constraints between prosodic and non-prosodic domains. The situation as it exists in Yurakaré may be typical for (poly)synthetic languages, where the word often is a highly grammaticalized structure potentially encompassing many different domains, such as morphology, syntax, and perhaps even pragmatics.

Donna Gerdts and Adam Werle present a taxonomy of clitics in Halkomelem, refining the traditional distinction between words, particles, and affixes. Applying several criteria, Gerdts and Werle show that, from a syntactic perspective, there are four clitic types (based on the parameters orientation and integration) while from a prosodic perspective, there are three clitic types (on the basis of syllabification, pausability, and contraction). In this way, using Prosodic Clitic Theory, the authors come to a more refined and satisfactory analysis of elements whose status lies somewhere in between words and affixes.

Acknowledgements The authors thank Geert Booij for valuable comments on this paper. All remaining errors are ours. 


\section{References}

Aikhenvald, A. Y. (2002). A grammar of Tariana. Cambridge: Cambridge University Press.

Anderson, S. R. (2005). Aspects of the theory of clitics. Oxford: Oxford University Press.

Bickel, B., Hildebrandt, K., \& Schiering, R. (2009). The distribution of phonological word domains: a probabilistic typology. In J. Grijzenhout \& B. Kabak (Eds.), Phonological domains: universals and deviations (pp. 47-75). Berlin: Walter de Gruyter.

Booij, G. (1983). Principles and parameters in prosodic phonology. Linguistics, 21, 249-280.

Booij, G. (1999). The phonology of Dutch. Cambridge: Cambridge University Press.

Booij, G. (2009). Lexical integrity as a formal universal: a constructionist view. In S. Scalise, E. Magni, \& A. Bisetto (Eds.), Universals of language today (pp. 83-100). Dordrecht: Springer.

Booij, G. (2010). Construction morphology. Oxford: Oxford University Press.

Brown, D., Chumakina, M., \& Corbett, G. (Eds.) (2012). Canonical morphology and syntax. Oxford: Oxford University Press.

Corbett, G. (2005). The canonical approach in typology. In Z. Frajzyngier, A. Hodges, \& D. S. Rood (Eds.), Studies in language companion series: Vol. 72. Linguistic diversity and language theories (pp. 25-49). Amsterdam: John Benjamins.

Corbett, G. (2006). Agreement. Cambridge: Cambridge University Press.

da Cruz, A. (2011). Fonologia e gramática do Nheengatú: a língua geral falada pelos povos Baré, Warakena e Baniwa. Utrecht: LOT.

Dixon, R. M. W. (1977). Some phonological rules in Yidin ${ }^{y}$. Linguistic Inquiry, 8(1), 1-34.

Dixon, R. M. W. (2002). The Jarawara language of Southern Amazonia. Oxford: Oxford University Press.

Dixon, R. M. W. \& Aikhenvald, A. Y. (Eds.) (2002). Word: a cross-linguistic typology. Cambridge: Cambridge University Press.

Dryer, M. (2013). Coding of nominal plurality. In M. Dryer \& M. Haspelmath (Eds.), World atlas of language structures online. Leipzig: Max Planck Institute for Evolutionary Anthropology. Available online at: http://wals.info/chapter/33. Accessed on 2013-11-21.

Elbert, S. H., \& Pukui, M. K. (1979). Hawaiian grammar. Honolulu: University of Hawaii Press.

Faller, M. (2002). Semantics and pragmatics of evidentials in Cuzco Quechua. PhD dissertation, Stanford University.

Guillaume, A. (2008). A grammar of Cavineña. Berlin: Mouton de Gruyter.

Hall, T. A. (1999). The phonological word: a review. In T. A. Hall \& U. Kleinhenz (Eds.), Studies on the phonological word (pp. 1-22). Amsterdam: John Benjamins.

Hall, T. A., Hildebrandt, K. A., \& Bickel, B. (2008). Introduction: theory and typology of the word. Linguistics, 46(2), 183-192.

Haspelmath, M. (2011). The indeterminacy of word segmentation and the nature of morphology and syntax. Folia Linguistica, 45(1), 31-80.

Haude, K. (2006). A grammar of Movima. PhD dissertation, Radboud University Nijmegen.

Inkelas, S. (1989). Prosodic constituency in the lexicon. PhD dissertation, Stanford University.

Inkelas, S. (1998). The theoretical status of morphologically conditioned phonology: a case study from dominance. In G. Booij \& J. van Marle (Eds.), Yearbook of morphology. 1997.

Kim, Y. (2008). Topics in the phonology and morphology of San Francisco del Mar Huave. PhD dissertation, University of California, Berkeley.

Magalhães, M. M. S. (2007). Sobre a morfologia e a sintaxe da língua Guajá (família Tupí-Guaraní). PhD dissertation, Universidade de Brasilia.

Matthews, P. H. (1991). Morphology (2nd ed.). Cambridge: Cambridge University Press.

McCarthy, J., \& Prince, A. (1993). Generalized alignment. In Yearbook of morphology (pp. 79-153).

Mithun, M. (2003). Pronouns and agreement: the information status of pronominal affixes. Transactions of the Philological Society, 101(2), 235-278.

Nespor, M., \& Vogel, I. (1986). Prosodic phonology. Dordrecht: Foris.

Pearce, E. (2012). Number within the DP: a view from Oceanic. In L. Brugé, A. Cardinaletti, G. Giusti, N. Munaro, \& C. Poletto (Eds.), Functional heads: the cartography of syntactic structures (Vol. 7, pp. 81-91). Oxford: Oxford University Press.

Peperkamp, S. (1997). Prosodic words. Amsterdam: Holland Institute of Generative Linguistics.

Prince, A., \& Smolensky, P. (1993). Optimality theory: constraint interaction in generative grammar. Unpublished manuscript, available at http://roa.rutgers.edu/files/537-0802/537-0802-PRINCE-0-0. PDF. 
Rankin, R., Boyle, J., Graczyk, R., \& Koontz, J. (2002). Synchronic and diachronic perspective on 'word' in Siouan. In R. M. W. Dixon \& A. Y. Aikhenvald (Eds.), Word: a cross-linguistic typology (pp. 180-204). Cambridge: Cambridge University Press.

Rice, K. (2011). Principles of affix ordering: an overview. Word Structure, 4(2), 169-200.

Schiering, R., Bickel, B., \& Hildebrandt, K. A. (2010). The prosodic word is not universal, but emergent. Journal of Linguistics, 46, 657-709.

Selkirk, E. O. (1984). Phonology and syntax: the relation between sound and structure. Cambridge: MIT Press.

Selkirk, E. O. (1995). The prosodic structure of function words. In J. Beckman, L. Walsh Dickey, \& S. Urbanczyk (Eds.), University of Massachusetts occasional papers: Vol. 18. Papers in optimality theory (pp. 439-469). Amherst, MA: GLSA.

Spencer, A., \& Luís, A. (2012). The canonical clitic. In D. Brown, M. Chumakina, \& G. G. Corbett (Eds.), Canonical morphology and syntax (pp. 123-150). Oxford: Oxford University Press.

Stevens, C. M. (2005). Revisiting the affixoid debate: on the grammaticalization of the word. In T. Leuschner, T. Mortelmans, \& S. De Groodt (Eds.), Grammatikalisierung im Deutschen (pp. 71-83). Berlin: Walter de Gruyter.

Stump, G. T. (2001). Inflectional morphology: a theory of paradigm structure. Oxford: Oxford University Press.

Thomas, D. D. (1962). On defining the 'word' in Vietnamese. Văn-Hóa Nguyêt-San, 11, 519-523.

Tuttle, S. (2008). Phonetics and word definition in Ahtna Athabaskan. Linguistics, 46(2), 439-470.

van Gijn, R. (2006). A grammar of Yurakaré. PhD dissertation, Radboud University Nijmegen.

Villafañe, L. (2004). Gramática Yuki. PhD dissertation, Radboud University Nijmegen.

Wackernagel, J. (1892). Über ein Gesetz der indogermanischen Wortstellung. Indogermanische Forschungen, 1, 333-436.

Wolfart, H. C. (1996). Sketch of Cree, an Algonquian language. In I. Goddard (Ed.), Handbook of North American Indians: Vol. 17. Languages (pp. 390-439). Washington: Smithsonian Institution.

Woodbury, A. (2002). The word in Cup'ik. In R. M. W. Dixon \& A. Y. Aikhenvald (Eds.), Word: a crosslinguistic typology (pp. 79-99). Cambridge: Cambridge University Press.

Zwicky, A. M. (1977). On clitics. Bloomington: IULC.

Zwicky, A. M. (1985). Clitics and particles. Language, 61(2), 283-305.

Zwicky, A. M., \& Pullum, G. K. (1983). Cliticization vs. inflection: English n't. Language, 59(3), 502513. 